\title{
EL DIEZMO Y LAS CATEDRALES EN ESPAÑA E INGLATERRA HACIA FINALES DE LA EDAD MEDIA
}

\author{
POR \\ JOSÉ JULIÁN HERNÁNDEZ BORREGUERO \\ Universidad de Sevilla \\ BEN DODDS, \\ Historia de la Universidad de Durham.
}

\begin{abstract}
RESUMEN: El artículo realiza un estudio comparado entre los sistemas de recaudación del diezmo español e inglés a finales de la Edad Media, tomando como referencia la administración del Cabildo Catedral de Sevilla y del monasterio de la Catedral de Durham. Los dos sistemas ofrecen algunas similitudes y también importantes diferencias, condicionadas, sobre todo, por los beneficiarios del diezmo: en el diezmo inglés el beneficio era para el párroco, y en el diezmo español participaban también la Corona, el obispo y el cabildo catedralicio (como gestor del impuesto).
\end{abstract}

PALABRAS CLAVE: Diezmo, gestión, Catedral, España, Inglaterra.

\section{TITHE AND THE CATHEDRALS OF SPAIN AND ENGLAND AT THE END OF THE MIDDLE AGES.}

ABSTRACT: This article is a comparative study of tithe collection in Spain and England at the end of the middle ages, based on the archives of the Cathedral Chapter of Seville and Durham Priory. A number of similarities are observable in the two systems but there are also important differences, especially concerning the recipients of tithe: in the English case, tithes were owed to the parish priest, but in the Spanish they were shared by the Crown, the bishop and the cathedral chapter (as manager of the tithe).

KEYWORDS: Tithe, management, Cathedral, Spain, England

$\begin{array}{ll}\text { Recibido/Received } & 05-10-2011 \\ \text { Aceptado/Accepted } & 14-04-2012\end{array}$


LA IMPORTANCIA DEL DIEZMO.

Durante décadas han venido realizándose una gran cantidad de investigaciones centradas en la realidad económica de los diezmos de la Iglesia católica. La mayoría de ellas, como veremos a continuación, han utilizado el estudio de los diezmos como un instrumento más que como un fin, como una manera de valorar la riqueza agropecuaria de los países, regiones, ciudades y su evolución a lo largo del tiempo.

Además de su interés como fuente para el historiador de la economía, el diezmo es una fuente fundamental para profundizar en la historia de la propia Iglesia. El impuesto era uno de los ingresos más importantes de los clérigos, influyendo en gran medida tanto en el equilibrio económico de las corporaciones eclesiásticas, como en el bienestar de sus miembros y en el de los demás clérigos ligados a estas instituciones, desde el más poderoso obispo hasta el más humilde párroco. En este ámbito, no se ha profundizado en el estudio del ciclo económico de la gestión del impuesto, su recaudación, almacenamiento y venta. En este artículo, abordamos estos asuntos desde una nueva perspectiva comparativa, estudiando el diezmo en dos territorios muy amplios, los reinos de España e Inglaterra, tomando como referencia los diezmos registrados en los archivos catedralicios de Sevilla y Durham, en un marco temporal muy concreto (finales de la Edad Media). Esta perspectiva pone de relieve las distintas maneras de gestión del diezmo y el gran impacto de estas diferencias sobre la Iglesia y sus clérigos.

Nadie pone en duda la antigüedad del diezmo como institución. Encontramos variadas referencias al impuesto en la Biblia: la primera, cuando Caín y Abel tuvieron que hacer un regalo a Dios (Génesis, 4). Durante todo el Antiguo Testamento se encuentran menciones más concretas en la ofrenda de Abraham a Melquisedec, en la que se cuantifica el tributo en el diez por ciento (Génesis, 14:18) o en el propio Deuteronomio (26:12).

En España, parece que el diezmo existiera de alguna forma (siempre voluntaria y que se pagaba "en conciencia") en las épocas romana tardía y visigótica, aunque sólo encontramos regulaciones sobre los sistemas de cobro y distribución de los ingresos desde el siglo VIII. ${ }^{1}$ En Inglaterra, encontramos evidencia para la imposición del diezmo como institución establecida ya en el siglo VII. ${ }^{2}$

${ }^{1}$ Latorre Ciria, J.M. 1992. Economía y religión. Las rentas de la catedral de Huesca y su distribución social (siglos XVI-XVII): Zaragoza; Díaz J.R. y Guinot, E. 2008. "La dîme dans l'Espagne médiévale", Actes des XXXes Journées Internationales d'Histoire de l'Abbaye de Flaran. Martín Riego, M, 1990. Diezmos eclesiásticos, rentas y gastos de la mesa arzobispal hispalense (1750-1800): Sevilla, sitúa la implantación voluntaria del diezmo a partir del siglo VI y su regulación desde el siglo XII.

2 McNeill J.T y Gamer. 1990. Medieval handbooks of penance: a translation of the principal 'Libri Poenitentiales' and selections from related documents: 212 New York.

Hispania Sacra, LXV

Extra II, julio-diciembre 2013, 81-111, e-ISSN: 1988-4265, doi: 10.3989/hs.2013.037 
También es reconocido el diezmo como una de las instituciones económicas más antiguas y con mayor continuidad temporal de toda Europa (durante la Edad Media, Moderna, incluso contemporánea). Pero su mayor importancia no reside en su antigüedad y longevidad, sino que, considerando que el diez por ciento de la producción agropecuaria de una región pasaba a manos de la Iglesia, podemos afirmar que el ciclo económico relacionado con la recaudación, almacenamiento y venta de los diezmos constituye uno de los principales flujos económicos y financieros de buena parte de los países europeos desde la Edad Media.

Se conservan grandes cantidades de documentación sobre diezmos, que parten desde la Baja Edad Media, referidas a cuentas de recibos, pleitos, contratos para la compra y venta de diezmos etc. Los documentos sobreviven en casi todos los países europeos y en algunos del Nuevo Mundo. Estos registros decimales son fundamentales para la historia de la Iglesia. El diezmo representaba la principal fuente de ingresos y de alimentos de los eclesiásticos, y, como tal, un aspecto importante, sin decir conflictivo, de las relaciones entre los parroquianos y sus curas. La gestión del diezmo muchas veces compartido entre el párroco y sus superiores, incluso con las autoridades seculares - tenía un gran impacto sobre la calidad de vida de los sacerdotes, el estado del mantenimiento de las iglesias mismas, de las vestiduras, los libros, beneficencia ${ }^{3}$, etc. También, el diezmo representa la conexión más importante entre la Iglesia y la economía. Muchas veces, resultó imposible que los párrocos, los obispos, los monasterios y otras corporaciones eclesiásticas pudieran consumir los ingresos diezmales ellos mismos: tenían que vender los productos. Antes de la industrialización y la urbanización de los últimos tres siglos, los productores consumían la parte mayor de la producción y vendían sólo una parte pequeña. En ese entorno, los diezmos vendidos representaban un porcentaje alto del grano y del ganado comercializado. Para los historiadores de la economía y de la empresa, no existe una fuente informativa y comparativa mejor. La comprensión del funcionamiento del diezmo es imprescindible para la Historia del Cristianismo, y para la Historia Económica.

A pesar de su gran importancia - y la cantidad y calidad del trabajo sobre los diezmos - no se ha profundizado en la gestión del impuesto en cada país y, menos aún, en las diferencias entre éstos. ¿Quien cobró el diezmo y para que lo usaron? ¿Cómo funcionaba el sistema de cobranza y la burocracia? Estas preguntas son importantes para entender el funcionamiento de la Iglesia, el sistema parroquial, y el abastecimiento de los beneficios. Todavía carecemos de un estudio de gran tamaño de la institución del diezmo en Europa, pero este artículo representa un primer paso hacia la historia comparativa. Ante la diversidad casi infinita de tipos,

${ }^{3}$ Conceptualmente se incluyen entre los objetivos del diezmo el socorro a los pobres en tiempos de calamidades: José Canga Argüelles, J. 1883. Diccionario de Hacienda, con Aplicación a España: 349 Madrid. 
dueños, compradores y beneficiarios de diezmo, hemos elegido lo que es probablemente el cuerpo más grande de documentos relacionados con el diezmo: el de la catedral de Sevilla en la Baja Edad Media y la Edad Moderna. Para la comparación, hemos elegido una de las comunidades religiosas más ricas de Inglaterra, y dueña de muchos diezmos: la catedral de Durham. Dos bases de documentación tan amplias nos permiten examinar la relación entre las catedrales y las parroquias en la cobranza y uso del diezmo, los productos diezmados, el consumo y la venta del fruto diezmal por los cabildos, y los sistemas burocráticos desarrollados para la cobranza del impuesto. Este estudio nos permite examinar bajo un nuevo prisma comparativo varios aspectos importantes de la vida religiosa del clero y de los fieles en dos partes de Europa muy distintas durante los siglos XV y XVI.

\section{DOS CATEDRALES}

La historia de la Catedral de Sevilla comienza con la reconquista de la ciudad en 1248. Desde sus inicios la sede hispalense siguió en sus constituciones el modelo de otras diócesis castellanas y, durante siglos, estuvo compuesto por 80 capitulares: 40 canónigos, 20 racioneros y 20 medio-racioneros. ${ }^{4}$ El rey Fernando III, muy religioso y muy ayudado en la conquista por la Iglesia, otorgó una innumerable cantidad de bienes, rentas y derechos a una serie de instituciones eclesiásticas. A partir de esa fecha y hasta 1285 los obispos recibieron sucesivas donaciones de mezquitas, rentas anuales, tierras de labranzas y otras propiedades inmobiliarias cercanas a la mezquita mayor que ya había sido transformada en Catedral. En 1285 se realizó una división entre patrimonio arzobispal y catedralicio (mesa arzobispal y mesa capitular). Durante los años siguientes el patrimonio del Cabildo no paró de crecer gracias a algunas compras, pero, sobre todo, a las donaciones en concepto de capellanía otorgada por numerosos fieles. ${ }^{5}$ Así a principios de la Era Moderna el patrimonio del Cabildo estaba perfectamente consolidado y no había sufrido apenas cambios desde finales de la Edad Media. Basándonos en un estudio reciente ${ }^{6}$ el Cabildo poseía unos 1.500 bienes, de los cuales unos 200 serían rurales $^{7}$ y 1.300 serían casas, tiendas y solares dentro de la ciudad de Sevilla. Prácticamente todos esos bienes estaban arrendados

${ }^{4}$ Costa y Belda, E. 1978. "Las Constituciones de don Raimundo de Lasaña para el Cabildo de Sevilla". Historia, Instituciones y Documentos.

${ }^{5}$ Rubio Merino, P. 1997. "Los archivos eclesiásticos de la archidiócesis de Sevilla". Conferencia dentro del "Curso sobre los Archivos Vaticanos y Sevillanos de la Iglesia Católica: del secreto a la apertura': Sevilla.

6 Hernández Borreguero, J.J. 2010. La Catedral de Sevilla: economía y esplendor (siglos XVI y XVII): 45 Sevilla.

7 Cifra similar a la estimada para finales del siglo XV por Montes RomeroCamacho, I. 1998. Propiedad y explotación de la tierra en la Sevilla de la Baja Edad Media: el patrimonio del Cabildo-Catedral: 344 Sevilla. 
proporcionando unos ingresos anuales enormes a la institución. Sin embargo, los ingresos que proporcionaba a la institución sólo eran la mitad de los mismos, gracias al importante volumen de los ingresos decimales que obtenía cada año. ${ }^{8}$

Durham es una de las sedes eclesiásticas más importantes en Inglaterra, después de los arzobispados de Canterbury y York. Desde el año 635 la pequeña isla de Lindisfarne, frente al palacio real de Bamburgh, en el litoral este del reino Anglo-Sajón de Northumbria, fue la sede de los poderosos obispos de Lindisfarne, incluyendo al famoso santo Cuthbert (quien murió en 687). Después de los ataques de los vikingos a finales del siglo VIII y a lo largo del siglo IX, trasladaron el cuerpo d el santo, llegando, al fin en 995, a Durham. Después de la invasión normanda, el primer obispo normando, William de Saint Calais, estableció una comunidad de monjes benedictinos en 1083 para custodiar la tumba del santo. ${ }^{9}$ Durante el siglo siguiente, la comunidad benedictina y los obispos de Durham separaron sus legados, por lo que coexistieron en el mismo templo catedralicio dos instituciones eclesiásticas distintas. Los monjes y los obispos fueron riquísimos, compartiendo entre los dos casi la mitad de la tierra entre los ríos Tyne y Tees y muchas más rentas, iglesias y otros bienes fuera de esta zona, desde Escocia al norte, hasta el palacio obispal en Londres al sur. Durante la Alta y la Baja Edad Media, la comunidad de Durham fue uno de los monasterios benedictinos más importantes en Inglaterra: hacia el fin del siglo XIII contaba con casi 120 monjes distribuidos en la casa central en Durham y en nueve dependencias. ${ }^{10}$

En 1539, Hugh Whitehead, el último prior de la comunidad monástica de Durham, con todos sus monjes, entregaron su monasterio, con todas sus propiedades -incluyendo los diezmos - al rey Enrique VIII. En 1541, refundaron la comunidad de la catedral como comunidad de clérigos seglares, un deán y capítulo. El mismo Hugh Whitehead fue nombrado como primer deán y más de la mitad de sus antiguos monjes recibieron el título de canónigos. A continuación recibieron el mismo legado que el antiguo monasterio, incluyendo todos los diezmos. ${ }^{11}$

\section{EL DIEZMO Y LA AUTORIDAD.}

${ }^{8}$ Hernández Borreguero, J.J: 231.

9 Rollanson D. y Dobson, R.B. 2004. "Cuthbert [St Cuthbert] (c.635-687)", Oxford Dictionary of National Biography, Oxford. 2011].

[http://www.oxforddnb.com/view/article/6976, visto el 17 de septiembre

10 Piper, A.J. 2005. "The size and shape of Durham's monastic community" en North-East England in the later middle ages: 154 Woodbridge.

11 Moorhouse, G. 2008. The last office: 1539 and the dissolution of a monastery: 185-200 London. 


\section{El modelo decimal en la Iglesia española}

En la Iglesia española la recaudación del diezmo está diseñada en torno a cada uno de los obispados. Estas diócesis emiten, con el consentimiento inicial de la Corona y el Papa, una normativa específica sobre todo el proceso, por la que tienen que regirse los feligreses (contribuyentes), las parroquias, obispados y catedrales (administradores).

Concretamente, en el caso de la diócesis de Sevilla el papa Alejandro IV es quien expide una bula en que le da todas sus veces y facultad de administración de los diezmos al Cabildo Catedral pocos años después de la reconquista de la ciudad y la instauración del Capítulo. Un siglo después será el rey don Pedro de Castilla quien faculta al citado Cabildo para que emita una normativa general y detallada (a modo de ley y constituciones ${ }^{12}$ ) para mejorar la administración del impuesto, siguiendo la tendencia reguladora que las diócesis castellanas más antiguas ya habían realizado bajo el reinado de Alfonso $X{ }^{13}$ Son muchas las diócesis españolas que delegaron la administración del impuesto (ámbito obispal) en su cabildo catedral. Los cabildos catedralicios fueron creados por la Iglesia de Roma en la Alta Edad Media para mejorar las relaciones con los feligreses; sus miembros, los canónigos, estaban liberados de funciones parroquiales, y consagraban su vida al estudio; ${ }^{14}$ al mismo tiempo, los obispos tomaban del cabildo sus principales consejeros y servidores para la dirección de la diócesis, hasta que prácticamente asumieron la labor de gobernar la diócesis ante la ausencia continuada de sus obispos; esta situación se mantuvo hasta el concilio de Trento, cuando se obligó a los obispos a residir en la diócesis.

Poco se ha estudiado sobre el reparto del fruto decimal de los obispados españoles. Existen estudios de diversas diócesis en las que transcriben la distribución teórica de los ingresos diezmales en un período de tiempo determinado. A pesar de ello puede recomponerse una regla general

12 Prólogo del Libro de Ordenanzas e Instrucciones sobre diezmos (16081679), Archivo Catedral de Sevilla, Mesa Capitular, 001312.

13 Nieto Soria J.M. 1984. "La conflictividad en torno al diezmo en los comienzos de la crisis bajomedieval castellana (1250-1315)", Anuario de estudios medievales: 211-235, detalla el esfuerzo realizado por el rey Alfonso $X$ por organizar, actualizar y detallar la regulación del impuesto, buscando, en su opinión, resolver los conflictos existentes debido a que no todos los feligreses estaban por la labor de pagar el diezmo, además de los continuos fraudes de los eclesiásticos a la hora de entregar a la Corona su parte correspondiente en el reparto decimal. Esas reformas regularon a fondo la normativa diezmal de las diócesis de Calahorra, Ávila, Córdoba, Cuenca, Burgos, Segovia, León, Salamanca, Badajoz y Orense.

${ }^{14}$ Rubio Merino, P. 2001. "Los archivos eclesiásticos". Iglesia y religiosidad en España: Historia y Archivos: Guadalajara. 
para todo el territorio español de ese reparto y una evolución histórica del mismo: ${ }^{15}$

a) Fase 1 (hasta el siglo XIII). Se identifican tres lotes: un tercio para los servidores de la iglesia local (ya sean párrocos, beneficiados de cualquier género o prestameras); un segundo tercio para la fábrica o mantenimiento de los templos adscritos a la parroquia donde se recauda el impuesto; y el tercero para el obispo. Por tanto dos terceras partes del fruto decimal se quedaban en la parroquia en cuestión y un tercio se destinaba a la sede episcopal correspondiente.

b) Fase 2. Durante el siglo XIII el papado comienza a conceder a la corona española la tercera parte de los diezmos correspondientes a los servidores y a la fábrica. Es decir, a partir de entonces comenzó el Rey a recibir un $22,22 \%$ de los ingresos diezmales.

c) Fase 3. Este reparto duró poco, pues las fábricas parroquiales tuvieron que compensar la pérdida del porcentaje de los servidores eclesiásticos.

d) Fase 4. Prácticamente en simultáneo al cambio anterior, el obispo cede una parte importante de su porción al cabildo catedralicio adscrito a su diócesis. Esta base teórica de reparto, con multitud de excepciones, ${ }^{16}$ se mantuvo vigente desde finales de la Edad Media hasta el final de la vigencia del diezmo, con mínimos retoques a la distribución y con pequeños matices en cada diócesis.

Para ilustrar cómo quedó este reparto definitivo traemos aquí los ilustrativos casos de las diócesis de Toledo y Sevilla, las dos mayores tanto por extensión como por el tamaño de sus ingresos:

${ }^{15}$ Aldea, Q. 1973. "La economía de las iglesias locales en la Edad Media y Moderna", Hispania Sacra, 26: 43-45.

${ }^{16}$ Así, por ejemplo, en la diócesis de Sevilla se documentan 33 parroquias o collaciones en las que el Cabildo Catedral apenas percibe un 3,3\% del montante recaudado y el obispo, nada. Ese $30 \%$ restante se destinaba algún clérigo de la diócesis elegido por el prelado (Ladero M.A. y González, M. 1978. Diezmo eclesiástico y producción de cereales en el reino de Sevilla (1408-1503): Sevilla). En contadas parroquias Cabildo y Arzobispo se reparten el $50 \%$ del total, o es el Arzobispo quien recibe íntegramente todo el fruto decimal" (Martín Riego, M. 1990. Diezmos eclesiásticos, rentas y gastos de la Mesa Arzobispal Hispalense (17501800): 27-29 Sevilla). 
Tabla 1. Reparto comparativo del diezmo de las diócesis de Sevilla y Toledo entre sus beneficiarios.

\begin{tabular}{|c|c|c|}
\hline Beneficiarios del diezmo & $\begin{array}{c}\text { Porcentaje } \\
\text { diócesis Toledo }\end{array}$ & $\begin{array}{c}\text { Porcentaje } \\
\text { diócesis Sevilla }\end{array}$ \\
\hline Arzobispo & $20,00 \%$ & $15,00 \%$ \\
\hline Cabildo Catedral $^{17}$ & $10,00 \%$ & $18,33 \%$ \\
\hline Deán $^{17}$ & $3,33 \%$ & $0^{18}$ \\
\hline Servidores $^{19}$ & $33,33 \%$ & $33,33 \%$ \\
\hline Tercias reales $^{\text {Fábricas de la collación }}$ & $22,22 \%$ & $22,22 \%$ \\
\hline Total & $11,11 \%$ & $11,11 \%$ \\
\hline
\end{tabular}

Como puede observarse una parte importante de los frutos decimales era destinada a los beneficiados parroquiales, concretamente un tercio de lo obtenido. Esta forma de retribución local institucionalizaba un sistema imperfecto lleno de desigualdades. Así no corrían la misma suerte los curas beneficiados de la parroquia de San Mateo de Jerez (quienes percibieron en concepto de cereales unas 21.396 fanegas en 1503) que los adscritos a la parroquia de San Dionisio de la misma ciudad jerezana (quienes se repartieron un total de 3.134 fanegas de cereal). ${ }^{20}$ Teniendo en cuenta que

${ }^{17}$ El deán es el miembro más importante del Cabildo y sustituto del obispo, a quien compete su elección. Sus funciones atienden al culto, a la organización y disciplina y a la administración económica de los bienes capitulares (Javier PérezEmbid, J. 1978. "El Cabildo Catedral de Sevilla en la Baja Edad Media", Hispania Sacra, 30: 143-181. Además controla los negocios del Cabildo, a sus mayordomos y contadores. El deán viene a ser como un "presidente del Cabildo", con funciones directivas y de control sobre el resto de capitulares y empleados (Hernández Borreguero, J.J. 2010: 27).

${ }^{18}$ En la diócesis de Sevilla el deán recibe una parte proporcional del reparto del Cabildo Catedral, al igual que los canónigos, racioneros y medio-racioneros, concretamente recibía el doble que un canónigo por su cargo (Ibídem, 105).

${ }^{19}$ En la diócesis de Sevilla los documentos no usan el término "servidores", sino que los denominan "beneficiados y prestameras" o "beneficiados" a secas. Para que una forma de retribución se considerara beneficio eclesiástico "debía tener los siguientes requisitos: ser erigido por la autoridad del prelado (arzobispo), llevar anexo una obligación de tipo espiritual, ser conferido por persona eclesiástica, ser otorgado a un clérigo, ser perpetuo y no poder ser retenido para sí)": Martín Riego, M. 1990: 32. Las prestameras era la parte del tercio destinada a los beneficiados que se dedicaba al sustento de diversos clérigos de la diócesis, 0 incluso lo percibía un beneficiado en concepto de estudios en alguna universidad, trabajo administrativo... (Ladero M.A y González, M. 1978: 24); también se aplicaban a "proporcionar una renta a los estudiantes pobres y a los que combatían contra los infieles y herejes (Martín Riego, M. 1990: 38).

20 Cálculos realizados a partir de los datos de Ladero M.A y González M. 1978: 112. 
en San Mateo había cuatro beneficiados y en San Dionisio eran tres ${ }^{21}$, obtendríamos que en el año 1505 correspondieron a cada uno de los beneficiados de San Mateo 5.349 fanegas de cereal, frente a las 1.044 fanegas de los de San Dionisio, casi cinco veces menos.

En definitiva, volviendo a la perspectiva de los cabildos catedralicios españoles, podemos concluir que éstos percibieron desde finales de la Edad Media un parte importante de los ingresos decimales, debido a que estas instituciones controlaron las diócesis ante las continuas ausencias de sus obispos. El porcentaje de los ingresos percibidos por los cabildos catedralicios variaba entre el $13,33 \%$ de la diócesis de Toledo, pasando por el $18,33 \%$ de la diócesis de Sevilla, hasta llegar al 25,92\% del obispado de Guadix. ${ }^{22}$

\section{El modelo decimal en la Iglesia inglesa.}

En Inglaterra los diezmos pertenecían en exclusiva al rector de cada parroquia. La regla general era que el párroco, como cura de almas en su circunscripción, recibía todos los diezmos. Sin embargo, a veces se asignaron los diezmos a otras instituciones eclesiásticas que disfrutaban del cargo de "rector titular" de la parroquia. Los diezmos no solían pertenecer a los obispos. Encontramos algunas excepciones, como los diezmos de las parroquias de Hambledon y East Meon (Hampshire), que pertenecían a los obispos de Winchester. Sin embargo, los obispos de Durham no tenían ingresos diezmales. Por ello, en la catedral de Durham, eran los monjes y sus sucesores, el deán y capítulo, los dueños de los diezmos.

Históricamente, en Inglaterra, hacia 1200, se había universalizado la propiedad de algunos diezmos rurales entre los monasterios: encontramos pocas instituciones monásticas sin ingresos diezmales. El proceso de asignación de los diezmos de una parroquia a una comunidad monástica fue regularizado por el Cuarto Consejo de Letrán en 1215: lo más importante fue el nombramiento de un vicario para ejercer la cura de almas, y la confirmación de la "retribución" de ese vicario. Los grandes capítulos monásticos de las catedrales inglesas acumularon gran cantidad de parroquias, de las cuales recibieron sus diezmos. En los principios del siglo XVI la comunidad benedictina de la catedral de Rochester, por ejemplo, tenían todos los diezmos de una parroquia en Buckinghamshire y tres más en Kent, además de una parte de los diezmos de unas veinte parroquias más en Kent. ${ }^{23}$ En los siglos XV y XVI, los monjes de Durham obtuvieron ingresos diezmales de más de treinta parroquias desde la frontera escocesa

21 Íbidem: 28.

22 Garzón Pareja, M. 1974. Diezmos y tributos del clero de Granada: 97 Granada: Archivo de la Real Chancillería.

23 Oakley, A. 1996. "Rochester Priory, 1185-1540" en Faith and fabric: a history of Rochester Cathedral: 604-1540. 
hasta Nottinghamshire. De estas parroquias, once estaban situadas en los alrededores de Durham. En el monasterio de Durham, los monjes-oficiales, es decir, los que cuidaban de algún aspecto de la vida del monasterio como el bursarius, el responsable de la comida de los monjes, o el hostillarius, el responsable de los huéspedes, compartían los diezmos entre ellos. Asignaban los diezmos de cada parroquia a un monje-oficial específico para los gastos de su negociado. Por ejemplo, el hostillarius recibía los diezmos de la gran parroquia de St Oswalds en Durham para sufragar los gastos de los huéspedes del monasterio.

Un aspecto destacado de este sistema de asignación de los ingresos parroquiales a un monasterio fue el derecho adquirido por el monasterio de elegir el vicario (en definitiva, el párroco). Este derecho de nombramiento (advowson) existía incluso en algunas parroquias donde los diezmos no pertenecían al monasterio. Por supuesto, este derecho representaba una influencia importante para los monjes. Por ejemplo, uno de los últimos actos del último prior de Durham (antes del cierre del monasterio en 1539) fue la elección de su sobrino como vicario de Heighington. ${ }^{24}$ Tales derechos podrían ser los orígenes de conflicto como, por ejemplo, en High Coniscliffe, una parroquia en la ribera norte del Tees, donde se asignaron los diezmos a los monjes de St Albans, un gran monasterio benedictino en el sur del país. Los obispos y los monjes de Durham, juntos con unos señores locales, se oponían a tal asignación. ${ }^{25}$

Normalmente, los vicarios recibían una porción de los diezmos, generalmente excluyendo los diezmos de mayores, o sea los de los cereales. Por ejemplo, en el 13 de noviembre 1325, el prior de Durham confirmó lo que pertenecía a los vicarios de Bishop Middleham. La porción del vicario incluía dos casas, los diezmos (excepto los de los cereales) y una cantidad de dinero pagado por costumbre por un hospital cerca de Durham. ${ }^{26}$ No se puede calcular fácilmente si los vicarios tenía bastante para vivir: la cantidad de productos recibida por el diezmo dependía del nivel de producción en la parroquia, del número de habitantes etc. Sabemos que los monjes cuidaban el abastecimiento de los vicarios, siguiendo los edictos del Cuarto Consejo de Letrán. Así, por ejemplo, el 28 de octubre 1337 el prior concedió $40 \mathrm{~s}^{27}$ al año al vicario de Dalton-le-Dale para recuperar la disminución de su dotación causada por el impacto de la guerra contra Escocia ${ }^{28}$ Es difícil evaluar el sistema desde la perspectiva de los fieles. Sin duda, a veces los fieles de alguna parroquia se encontraron con un mal vicario. En 1500, Thomas Swalwell, un monje de Durham y rector del colegio universitario en Oxford del monasterio de Durham, requirió a Thomas

\footnotetext{
${ }^{24}$ Moorhouse, G. 2008: 185.

25 Prior's Register II, f. 53v-54r.

26 Prior's Register II, f. 97r.

2740 soldidi, shillings o chelines.

28 Prior's Register II, f. 110r.
} 
Patonson, vicario de la parroquia de Frampton en Lincolnshire, a vivir en su parroquia, como dijo la ordenanza de la dotación del vicario. Patonson rehusó porque creía que los fieles en la parroquia eran "hombres sin razón". ${ }^{29}$ De hecho, parece que el problema era que Patonson vivía en Durham, porque, en 1507, cambió su beneficio con el vicario de Pittington, una parroquia al lado de la ciudad de Durham. ${ }^{30}$ Por supuesto, los vicarios se encontraban bajo el mismo sistema de control del obispo en torno a la cura de almas. Por ejemplo, en 1498 el obispo de Durham reprendió a los rectores, vicarios y capellanes de la ciudad de Durham por el descuido a los fieles en tiempos de la peste. ${ }^{31}$

\section{EL HECHO IMPONIBLE: EL PRODUCTO AGRARIO.}

En Inglaterra, los ingresos diezmales de una parroquia eran variados y complicados de recaudar. En teoría, diezmaban todos los productos que "crecían" durante un año: lo que se cultivaba en los campos, los productos provenientes de los animales y los animales nuevamente nacidos. Sin embargo, en la práctica el objeto impositivo dependía de las costumbres de cada parroquia. La producción mineral también estaba sujeta al diezmo, aunque su cuantificación, como veremos, era especialmente problemática. ${ }^{32}$ En líneas generales, los ingresos diezmales en parroquias inglesas estaban compuestos de los diezmos de cereales ${ }^{33}$ (llamados decimae garbarum o "'diezmos de gavillas"), los diezmos de lana y los diezmos menudos (donde se englobaban genéricamente el resto). Es evidente que hubo una gran variedad de diezmos menudos. Como se ha dicho antes, normalmente los vicarios cobraban los diezmos menudos, pero no existía un sistema normativo uniforme en todas parroquias. Merece la pena analizar varios casos específicos para mostrar los productos diezmados, y quien los cobraba.

Así, por ejemplo, a fines del siglo $X V$, el vicario de Hornsea, una parroquia en la costa del este de Inglaterra dependiente del monasterio de St Mary en York, recibió los diezmos de corderos, de lana, de cochinillos, de pollos, de cáñamo, de lino, de huevos, de manzanas y de peras. La documentación preparada por los clérigos de la parroquia incluye los nombres de todos los fieles que pagaron corderos, lana y cochinillos

29 Prior's Register V, ff. 57r-V.

30 Prior's Register V, ff. 84r - 85r.

31 Prior's Register V, ff. 53v-54r.

32 Swanson, R.N. 1989. Church and Society in Late Medieval England: 211 Oxford: Blackwell Publishers.

${ }^{33}$ En el caso del diezmo de los cereales se recaudaba el diezmo antes de la deducción del grano para la semilla. Por tanto, un 10 por ciento de la cosecha es, en realidad, una proporción mucho más alta de la cosecha disponible por el agricultor. 
diezmales. ${ }^{34}$ Normalmente, los vicarios recaudaban también los "diezmos personales", pagados sobre salarios y beneficios del comercio y de la industria, los cuales adquirían un alto importe en las grandes ciudades. Por ejemplo, en 1535 el vicario de St. John-in-Bedwardine en Worcester recibió $£ 8$ 13s. 4d. de diezmos personales, más de la mitad de sus ingresos diezmales. ${ }^{35}$

Los diezmos menudos representaban un problema para los rectores titulares de las parroquias asignadas a los monasterios y catedrales. Los monjes de Durham, por ejemplo, no querían recibir miles de huevos diezmales que no podían consumir, como pasó en el monasterio de Selby (West Yorkshire) en 1416-17. ${ }^{36}$ Por esa razón, los rectores titulares solían recaudar sólo los diezmos de los cereales. Estos eran los diezmos más valiosos y los más fáciles para recaudar en las parroquias. Por ejemplo, en la parroquia de St Oswald en la ciudad de Durham a mediados del siglo XV, los diezmos menudos, incluyendo los de corderos, terneros y lana alcanzan un valor de $£ 1316 \mathrm{~s}$. 4d. y los diezmos de cereales recaudados por los monjes de la misma parroquia valieron más de $£ 21$, excluyendo otros diezmos de cereales de partes específicas de la parroquia reservados para los oficiales de los monjes. ${ }^{37}$

En general, sabemos muy poco de los diezmos personales, y otros diezmos menudos, porque es poca la documentación de los vicarios que se conserva. En el caso de las parroquias del Priorato de Durham, no cabe duda de que tales diezmos personales existían: un pleito de 1345 nombra a Bona, la mujer de Ranulf, un clérigo, que no pagaba sus diezmos personales en la parroquia de St Oswald en la ciudad de Durham. ${ }^{38}$ De hecho, sabemos mucho más de los diezmos menudos en St Oswald's que en las otras parroquias porque los vicarios recibieron un salario en vez de recibir directamente los diezmos menudos. ${ }^{39}$ Así en el período 1447-8 podemos ver que, aparte de los cereales, lana y terneros, los "procuradores" de la parroquia - o sea, los oficiales al servicio de los monjes de Durham que trabajaban en la parroquia - recibieron diezmos de heno, lino, cáñamo, ciervos, cebollas, gansos y pollos y los diezmos personales. ${ }^{40}$

${ }^{34}$ Kent et al. 2002. "North Division: Hornsea", A History of the County of York East Riding: Volume 7: Holderness Wapentake, Middle and North Divisons: 273295. [http://www.british-history.ac.uk/report.aspx?compid=16153, visto el 29 de septiembre 2011]. Heath, P.M.A. 1964. Medieval Clerical Accounts: York.

${ }^{35}$ Little, A.G. 1945. English Historical Review, 60: 86.

36 Swanson, R.N. 2008. "A universal levy: tithes and economic agency" en Agriculture and Rural Society after the Black Death: Common themes and regional variations: $90-91$ Hatfield.

37 Durham Cathedral Muniments, hostiller's account 1447-8; Harvey, M.M. Lay Religious Life in Late Medieval Durham: Woodbridge.

38 Ibídem: 12.

39 Ibídem: 6-7.

40 Ibídem: 25.

Hispania Sacra, LXV

Extra II, julio-diciembre 2013, 81-111, e-ISSN: 1988-4265, doi: 10.3989/hs.2013.037 
El producto más controvertido en Durham era el carbón. Hasta el último tercio del siglo XVI, la extracción de carbón era todavía una industria pequeña en el noreste de Inglaterra pero los priores de Durham guardaban celosamente sus derechos a percibir los diezmos del carbón. Hubo una serie de pleitos en los cuales los mineros de Durham intentaron probar que no existía el derecho a percibir el diezmo sobre el carbón, pero perdieron todos esos pleitos. ${ }^{41}$

En España los ingresos sujetos al impuesto diezmal sólo tienen base agropecuaria. La doctrina tradicionalmente divide los diezmos en prediales y personales. ${ }^{42}$ Los primeros serían los que se recogen de los predios, campos, viñas, huertas, árboles y animales. Los personales se refieren a los diezmos percibidos por las cosas adquiridas por el propio trabajo, negocio y oficio, pero relacionados con el ámbito agrícola y ganadero. Los libros de diezmos ofrecen listados de productos sujetos al diezmo que permiten conocer la riqueza productiva de la diócesis de Sevilla: trigo, cebada, vid, aceitunas, garbanzos, huertas, miel, aves (pollos, pavos, pichones), cerdos, cabritos, becerros, potros, mulas, corderos, queso, lana, cera, etc. Por tanto, a diferencia del sistema diezmal inglés, estaban exentos de tributación los frutos obtenidos de la minería y de otras profesiones distintas a las relacionadas con el negocio agropecuario.

Como en Inglaterra, existía la distinción entre los diezmos de mayores y de menudos. Los primeros aglutinan a los que se pagan de cereal, vid $^{43}$ y otros frutos que se cosechan en abundancia. El resto de productos sujetos al diezmo se denomina los menudos. ${ }^{44}$ En la diócesis de Sevilla, al igual que en la mayoría de las otras españolas la mayor parte de los ingresos diezmales proceden de los cereales.

Otro aspecto interesante era el cálculo de la cuota impositiva a recaudar. En los productos que se cosechaban la dificultad era menor: el diezmo a satisfacer era una décima parte de la producción obtenida. La Iglesia admitía el sistema de "auto-declaración", por el que el contribuyente señala cuál es el diez por ciento de su cosecha. Así, por ejemplo, encontramos un documento en el que el Cabildo Catedral explica el proceso para cobrar los diezmos del vino de Jerez a su administrador allí situado, obligándole a registrar en un libro "acabada la vendimia (...) procure que todos declaren lo que deben para que se pongan sus declaraciones en el libro mayor" ${ }^{\prime 4}$.

41 lbídem: 79.

42 Martín Riego, M. 1990: 69 hace referencia a la obra de Barbosa (1712).

43 El Cabildo Catedral de Sevilla denominaba erróneamente "diezmos del pan" a los del trigo y cebada, y "diezmos del vino" a los de la uva.

44 Morales Alonso, J.P. 1883. Tratado de Derecho Eclesiástico general y particular de España: 796 Sevilla: s.e..

${ }^{45}$ ACS, Biblioteca Capitular, 64-7-100. 
La complejidad para cuantificar los diezmos a percibir crecía en otros tipos de diezmos, por ejemplo, los relacionados con el ganado. Así, aunque la Ley de la Casa de Cuentas (LCC) detalla decenas de excepciones y matizaciones, en la norma número 47 (folio $23 r$ ) se señala que "los que hubieren de dezmar los ganados (...) que los diezmen en esta manera: que de diez reses den una al diezmo, y sea buena según son tenidos. $Y$ de los que no llegaren a diez, que paguen el diezmo según el valor del apreciamiento; y este apreciamiento lo haga el señor del ganado y el arrendador con dos hombres buenos juramentados, sabedores de ello (...)". Otro de los problemas es que las cabezas de ganado iban naciendo y muriendo, por lo que algunas normas especifican cuándo realizar el inventario: "que los borricos y potricos y cochinos que se cuenten y anden de San Martín a San Martín de cada año según que antiguamente así se acostumbró, lo cual queremos que se use en esta manera: los que nacieron o nacieren desde el día de San Martín del año próximo pasado hasta el día de San Martín de este año presente (...) se entienda pertenecer los diezmos de ellos a estas rentas de este presente año (...)".

Otro aspecto importante es cómo se percibe el diezmo. El diezmo de cereal era cobrado en especie, en grano "nuevo y limpio". ${ }^{46}$ Otro de los diezmos importantes, el de la vid, se cobraba en metálico. Sin embargo el diezmo del aceite se cobraba en aceitunas, aunque se admitía el pago en aceite líquido; finalmente el administrador del cobro valoraba tanto la aceituna y el aceite en moneda, restaba los gastos de gestión y distribuía entre los beneficiados un importe en metálico. ${ }^{47}$ En cuanto a los menudos, el ingreso diezmal también llegaba a sus destinatarios siempre en moneda.

También a diferencia del sistema de recaudación y reparto británico, en España, los beneficiarios de cada una de las parroquias recibían un porcentaje fijo (como hemos visto más arriba) de todos los diezmos percibidos, con independencia de que provinieran de cereales, de ganado $u$ otro producto, ya fueran cobrados en especie o en moneda.

\section{LOS INGRESOS DIEZMALES EN LAS CATEDRALES DE SEVILLA Y DURHAM (1534)}

Como hemos indicado, no resulta fácil valorar los ingresos diezmales totales del Priorato de Durham para un año a partir de la agregación de todos los datos parroquiales. Son pocos los años en los que se conservan las cuentas de todos los oficios del monasterio; tampoco sobrevive mucha información sobre los ingresos en especie, y menos todavía de los ingresos diezmales de animales. Sin embargo, en 1534 Enrique VIII promulgó una ley desviando los ingresos del primer año de un beneficio eclesiástico hacia la Corona. Para conocer mejor el valor de todos los beneficios, mandó realizar un inventario de los mismos, el cual se denominó el Valor Ecclesiasticus

46 La Ley de la Casa de Cuentas (LCC), folio 13.

47 Hernández Borreguero, J.J. 2010: 63.

Hispania Sacra, LXV

Extra II, julio-diciembre 2013, 81-111, e-ISSN: 1988-4265, doi: 10.3989/hs.2013.037 
(1535). ${ }^{48}$ Este gran documento facilita una valoración de todos los diezmos pertenecientes a los monjes de Durham, que resumimos en la siguiente tabla:

Tabla 2. Los diezmos pertenecientes a los monjes de Durham en 1535

\begin{tabular}{|c|c|c|}
\hline $\begin{array}{l}\text { Parroquia } \\
\text { (pertenecientes a los } \\
\text { monjes de Durham o } \\
\text { de alguno de los } \\
\text { monasterios } \\
\text { dependientes) }\end{array}$ & $\begin{array}{lr}\text { Valor de los } \\
\text { diezmos } \\
\text { pertenecientes } \\
\text { los monjes }\end{array}$ & $\begin{array}{l}\text { Valor de los diezmos } \\
\text { pertenecientes a los } \\
\text { vicarios }\end{array}$ \\
\hline $\begin{array}{l}\text { Durham St Oswald's } \\
\text { (Durham) }\end{array}$ & $£ 10$ 9s. 8d. & $\begin{array}{l}\text { [Los vicarios no } \\
\text { cobraban una porción } \\
\text { fija de los ingresos } \\
\text { diezmales] }\end{array}$ \\
\hline $\begin{array}{l}\text { Jarrow (porción } \\
\text { perteneciente a } \\
\text { Durham) }\end{array}$ & $£ 29$ 16s. 8d. & $\begin{array}{llr}\text { Los } & \text { vicarios } & \text { no } \\
\text { cobraban una porción fija] }\end{array}$ \\
\hline $\begin{array}{l}\text { Southwick [una villa } \\
\text { en la parroquia de } \\
\text { Wearmouth] } \\
\text { (Durham) }\end{array}$ & $£ 5$ 6s. 8d. & $\begin{array}{llr}\text { Los } & \text { vicarios } & \text { no } \\
\text { cobraban una porción fija] }\end{array}$ \\
\hline $\begin{array}{l}\text { Monk Hesleden } \\
\text { (Durham) }\end{array}$ & $£ 22$ 16s. 8d. & $£ 4$ 17s. 4d. \\
\hline $\begin{array}{l}\text { Dalton le Dale } \\
\text { (Durham) }\end{array}$ & $£ 15$ 17s. 8d. & $£ 6$ 1s. 6d.* \\
\hline Pittington (Durham) & $£ 26$ 16s. 8d. & $£ 13$ 16s. 0d.* \\
\hline Billingham (Durham) & $£ 26$ 13s. 4d. & $£ 11$ 8s. 4d.* \\
\hline Aycliffe (Durham) & £18 13s. 4d. & $\begin{array}{l}\text { [El Valor no contiene } \\
\text { información sobre la } \\
\text { porción de los vicarios de } \\
\text { Aycliffe] }\end{array}$ \\
\hline Heighington (Durham) & $£ 37$ 3s. 4d. & $£ 15$ 10s. 0d.* \\
\hline $\begin{array}{l}\text { Kirk Merrington } \\
\text { (Durham) }\end{array}$ & $£ 23$ 14s. 8d. & $£ 14$ 0s. Od. \\
\hline Berwick (Durham) & $£ 23$ 0s. Od. & $\begin{array}{ll}\text { [Los vicarios } & \text { no } \\
\text { cobraban una porción fija] }\end{array}$ \\
\hline $\begin{array}{l}\text { Norham y varias villas } \\
\text { en Holy Island } \\
\text { (Durham) }\end{array}$ & $£ 76$ 13s. 4d. & $\begin{array}{l}\text { [Los vicarios no } \\
\text { cobraban una porción fija] }\end{array}$ \\
\hline Edlingham (Durham) & $£ 11$ 18s. 8d. & $£ 1$ 3s. $5 \frac{1}{2} 2$ d. \\
\hline
\end{tabular}

48 Scarisbrick, J. 1960. "Clerical taxation in England, 1485-1547", Journal of Ecclesiastical History, 11: 50-51. 


\begin{tabular}{|c|c|c|}
\hline Bedlington (Durham) & $£ 9$ 0s. Od. & £1 6s. 8d. \\
\hline $\begin{array}{l}\text { Bywell St Peter } \\
\text { (Durham) }\end{array}$ & $£ 14$ 0s. 0d. & 19s. 93/4d. \\
\hline Northallerton (Durham) & $£ 36$ 6s. 8d. & $£ 23$ 0s. 8d. \\
\hline Eastrington (Durham) & $£ 22$ 0s. 0d. & $£ 1$ 4s. $11 \frac{1}{2} 2$ d. \\
\hline Giggleswick (Finchale) & $£ 44$ 0s. 0d. & $£ 2$ 2s. 4d. \\
\hline $\begin{array}{l}\text { Bishop Middleham } \\
\text { (Finchale) }\end{array}$ & £16 13s. 4d. & $£ 6$ 0s. Od. \\
\hline $\begin{array}{l}\text { Jarrow (porción } \\
\text { perteneciente a los } \\
\text { monjes de Jarrow) }\end{array}$ & £19 13s. 4d. & $\begin{array}{ll}{[\text { Los }} & \text { vicarios no } \\
\text { cobraban una porción fija] }\end{array}$ \\
\hline $\begin{array}{l}\text { Wearmouth (porción } \\
\text { perteneciente a los } \\
\text { monjes de } \\
\text { Wearmouth) }\end{array}$ & £18 5s. 0d. & $\begin{array}{ll}{[\text { Los vicarios }} & \text { no } \\
\text { cobraban una porción fija] }\end{array}$ \\
\hline $\begin{array}{l}\text { Holy Island (Holy } \\
\text { Island) }\end{array}$ & $£ 35$ 3s. Od. & $\begin{array}{l}\text { [Los vicarios no } \\
\text { cobraban una porción fija] }\end{array}$ \\
\hline Lytham (Lytham) & £9 13s. 11d. & $\begin{array}{l}\text { [Los vicarios no } \\
\text { cobraban una porción fija] }\end{array}$ \\
\hline
\end{tabular}

* En estos casos, los ingresos diezmales de los vicarios incluyen ingresos de pequeñas tierras o de casas en arrendamiento.

Según la información del Valor, presentada aquí el la tabla 2, los monjes de Durham y de sus monasterios dependientes cobraban £553 15s. 11d. cada año en concepto de diezmos. En al menos 13 de las 21 parroquias (contando Jarrow y Monkwearmouth, divididas entre los monjes de Durham y los de los monasterios dependientes en las parroquias, como dos parroquias), los vicarios cobraron una porción de los diezmos. El valor de los diezmos perteneciente a los vicarios variaba mucho en cada parroquia en comparación con el asignado a los monjes. En el caso de Northallerton en Yorkshire, los diezmos de los vicarios tenían un valor superior en un 60 por ciento al de los monjes; en el caso de Giggleswick, también en Yorkshire, el vicario apenas percibía unos ingresos que representaban solo el 5 por ciento de los frutos monacales. En definitiva, los ingresos diezmales totales de las parroquias (incluyendo la parte de los monjes y de los vicarios) ascendían a $£ 655$ 6s. $113 / 4$ d.

Como hemos explicado, el Valor Ecclesiasticus era una encuesta realizada por la Corona con la intención de cobrar una porción de los ingresos de los monasterios y de los beneficios eclesiásticos, por lo que, probablemente, a los monjes les convino valorar a la baja sus diezmos. Como veremos, también hay que considerar que en muchos casos los monjes vendían los diezmos mediante subasta, por lo que la cantidad de dinero anotada en el Valor Ecclesiasticus podría ser el importe pagado por el comprador del diezmo. Todo parece indicar que los burócratas encargados de esta valoración de los diezmos intentaron llegar al valor típico de los 
ingresos. ${ }^{49}$ Además podemos añadir que se conserva una cuenta de 1536-7 con ingresos diezmales para diez de las parroquias en la tabla 2. La cuantía que aparece en el registro contable es un 19 por ciento más alto que en el Valor. ${ }^{50}$ Esta diferencia podría ser efecto de un aumento en la producción agrícola entre 1534-5 y 1536, pero también podría indicar la infravaloración en el Valor.

A pesar de dificultades mencionadas, podemos usar el Valor Ecclesiasticus como base para una valoración de los diezmos cobrados por los monjes. Si tomamos los datos del Valor como mínimo, y consideramos que los valores reales podrían ser superiores en un 19 por ciento (como máximo hipotético a partir de los datos de 1536), parece que los diezmos en las parroquias perteneciendo a los monjes de Durham tenían un valor entre $£ 655$ 6s. $113 / 4$ d. y $£ 779$ 17s. $3^{1 / 2}$ d. y que los monjes cobraban entre $£ 553$ 15s. 11d. y $£ 659$ 0s. 4d. Expresado en kilogramos de trigo (usando el precio de trigo de 1534) el valor de los diezmos de las parroquias estaría en una banda entre 433.424-515.774 kilos, y la porción de los monjes se movería entre los 366.261 y los 435.850 kilos de trigo. ${ }^{51}$

El estudio comparativo para el mismo período en la diócesis de Sevilla, como veremos, es complejo:

En primer lugar, hay que considerar que la diócesis de Sevilla estaba dividida en más de 100 collaciones, agrupadas en 20 vicarías. ${ }^{52}$ Los diezmos percibidos por el Cabildo Catedral se dividen, administrativamente, entre los relacionados con cereales (trigo y cebada) y el resto, por lo que los registros se multiplican anualmente por dos.

En segundo lugar, el Cabildo recibe como ingresos decimales trigo, cebada y dinero. Parte del dinero procede de la venta de algunas partidas significativas de cereales.

${ }^{49}$ Robinson, W.R.B. 1983. "The Valor Ecclesiasticus of 1535 as evidence of agrarian output: tithe data for the deanery of Abergavenny", Bulletin of the Institute of Historical Research, 56: 18-23.

50 Durham Cathedral Muniments, cuenta del bursarius, 4 junio 1536, 20 mayo 1537.

51 Conversión así: 1 quarterius = 291 litros. Precio del trigo en 1534 de Clark. G. 2004. "The price history of English agriculture, 1209-1914". Research in Economic History, 22.

Posteriormente hemos considerado la equivalencia por la cual una fanega de grano de trigo ocuparía un recipiente de 55,5 litros, y esta cantidad puede estimarse en 44,4 kilogramos de peso (Ladero M.A. y González, M. 1978: 73).

52 Hernández Borreguero, J.J: 2010: 14. 
Del total de los diezmos percibidos por el Cabildo, no se reparte el total entre sus miembros, sino que se retiene una pequeña parte (no reglada por ninguna norma) para afrontar una serie de gastos de la institución capitular.

A continuación exponemos los datos conservados sobre los ingresos diezmales del Cabildo Catedral de Sevilla en 1534: en concepto de "pan" al Cabildo correspondían ${ }^{53} 32.414$ fanegas y 8 almudes de trigo y 11.202 fanegas y 8 almudes de cebada. ${ }^{54}$ En moneda el Cabildo debía ingresar 7.601.743 maravedíes.

Como hemos señalado, tras las divisiones y cálculos internos de la institución, se obtenía la base de reparto. Esta cantidad se repartía a partes iguales, denominadas canonjías, parte que percibían proporcionalmente los miembros capitulares, según su condición de dignidad, canónigo, racionero y medio-racionero. ${ }^{55} \mathrm{~A}$ efectos administrativos, lo percibido en concepto de diezmos tenía dos componentes: una parte fija, por el simple hecho de disfrutar de la condición de capitular, denominada grosa; y otra parte fija, en función de la asistencia a un mínimo de una serie de cultos que se celebraban en la Catedral, denominada misadas. ${ }^{56}$ La canonjía de 1534 dio derecho a las siguientes percepciones: 412 fanegas y 11 almudes de trigo, y 141 fanegas y 11 almudes de cebada; y 50.147 maravedíes.

Finalmente resumimos los datos sobre los ingresos diezmales de la diócesis de Sevilla en 1534, con las conversiones oportunas, en la siguiente tabla:

Tabla 3. Los ingresos diezmales de la diócesis de Sevilla en 1534.

\begin{tabular}{|l|l|l|}
\hline INGRESOS DEL CABILDO & Total & En kgs. \\
\hline Trigo & $\begin{array}{l}34214,6 \\
\text { fanegas }\end{array}$ & 1.519 .128 \\
\hline
\end{tabular}

53 Los datos se obtienen de libros previsionales, en los que no se contabilizan los cobros, sino las cantidades que teóricamente habría de recibir. Normalmente el importe a percibir del realmente percibido variaba muy poco, aunque partidas importantes tardaban en hacerse líquidas desde un año hasta tres de retraso (Idem).

54 ACS, Mayordomía, 00011, apartado "cargo de pan". El desglose de lo recaudado en cada parroquia aparece en ACS, Mayordomía, 01575.

55 Como ya señalamos, el Cabildo estaba compuesto por 80 capitulares: 40 canónigos, 20 racioneros y 20 medio-racioneros; entre los canónigos se elegían 9 dignidades, entre los que figuraban el propio deán, chantre, tesorero, maestrescuela y los arcedianos (Costa y Belda, E. 1978). Los canónigos disfrutaban de una canonjía; las dignidades, dos; los racioneros, dos terceras partes de una canonjía; y los medio-racioneros, un tercio (Hernández Borreguero, J.J: 2010).

56 En la práctica, todos los miembros capitulares conseguían cobrar íntegramente las misadas gracias a una serie de permisos y vacaciones. 
FINALES DE LA EDAD MEDIA

\begin{tabular}{|c|c|c|}
\hline Cebada & $\begin{array}{l}11202,6 \\
\text { fanegas }\end{array}$ & $497.395,4$ \\
\hline El resto ${ }^{57}$ & $7.601 .743 \mathrm{mrs}$ & 2.250 .116 \\
\hline Total & & 4.266 .640 \\
\hline INGRESOS POR CANONJÍA & Total & En kgs. \\
\hline Trigo & 412,9 fanegas & $18.332,76$ \\
\hline Cebada & 141,9 fanegas & $6.300,36$ \\
\hline El resto & $50.147 \mathrm{mrs}$ & $14.843,51$ \\
\hline Total & & $39.476,63$ \\
\hline
\end{tabular}

Como puede verse a simple vista, el Cabildo hispalense obtuvo ese año más de 4 millones de kilogramos de cereal (la mayor parte de trigo). Por tanto, quiere decir que sus ingresos diezmales podrían ser 9-10 veces superiores a los del capítulo de Durham.

\section{LA VENTA DE LOS DIEZMOS}

En Durham los monjes vendían los diezmos que no recaudaban directamente. Mediante este procedimiento la institución renunciaba a parte de los frutos a cambio de que fueran los compradores - también llamados a veces arrendatarios - quienes asumieran el cobro del mismo a cambio de un beneficio.

Los sirvientes de los monjes, y a veces los monjes mismos, visitaban las parroquias en cuestión para la venta anual. ${ }^{58}$ Parece que las ventas tenían lugar antes de la cosecha por un sistema de subastas, aunque se ha conservado muy poca información sobre este sistema. Normalmente esta venta de diezmos de cada parroquia se realizaba cada año, aunque hemos encontrado casos en los que se contrataba por varios años. ${ }^{59}$ Así por ejemplo, en 1530, los monjes de Jarrow, un pequeño monasterio dependiente de Durham situado en la orilla sur del río Tyne, vendieron los diezmos de lino, heno y cáñamo de Hedworth de 1530, 1531 y 1532 a John Mathow por $£ 4$ al año. ${ }^{60}$

57 El Cabildo vendió partidas mezcladas de trigo y cebada durante el año 1534 con un precio que oscilaba entre los 120 y 210 maravedíes cada fanega (ACS, Mayordomía, 00011, apartado "cargo del comunal"). Hemos estimado un precio medio de 150 maravedíes/fanega a efectos de las oportunas equivalencias.

58 Por ejemplo, los gastos de las visitas del bursarius y sus sirvientes a Northumberland para la venta de los diezmos están registrados en Durham Cathedral Muniments, bursar's account, 1449-50, Expense necessarie.

59 Dodds, B. 2007. Peasants and production in the medieval North-East: the evidence from tithes, 1270-1536: 24-25 Woodbridge.

60 Durham Cathedral Muniments, account of the Master of Jarrow, 1531-2. 
Los monjes solían registrar el nombre del comprador del diezmo en la contabilidad. Los nombres revelan compradores de varios tipos. A veces todos los agricultores de una población compraron los diezmos de su propia parroquia, como en el caso de Willington, en la orilla norte del río Tyne, a los principios del siglo XVI. ${ }^{61}$ En otros casos, el arrendatario del feudo de los monjes en una parroquia compró los diezmos, como en la parroquia de Aycliffe, al sur de Durham, en la misma época. ${ }^{62}$ Algunos compradores eran hidalgos, como el caballero Thomas Tempest que compró los diezmos de Brafferton, también en Aycliffe, en 1519 y 1536. Tempest provenía de una familia noble que tenía la mayoría de sus tierras en Yorkshire. ${ }^{63}$ Otros eran clérigos, como el vicario de Northallerton que compró los diezmos de su propia parroquia en la misma época, una gran inversión de dinero cada año. Se nota que los vicarios podían aprovechar de su familiaridad con los fieles para recaudar los diezmos de manera eficiente. ${ }^{64}$ La inmensa mayoría de los compradores eran hombres pero, de vez en cuando, se encuentra una mujer compradora, como en el caso de los diezmos de Crook Hall en la ciudad de Durham, comprados por la viuda de Radulph Billingham en $1528 .^{65}$

Grandes monasterios, como el de Durham, necesitaban muchos productos agrícolas para el abastecimiento de los monjes y tal necesidad representaba un gran problema de gestión. Los monjes tenían que decidir si iban a llenar su granero con los productos cosechados en sus fincas y con los recibidos de los diezmos, o si iban a arrendar las tierras y los diezmos y comprar su comida en el mercado. En el siglo XIV, se observan cambios importantes en el sistema de abastecimiento con las crisis económicas causadas por la guerra y la peste negra. Con una nueva época de precios bajos y salarios altos, los monjes de Durham, como otros terratenientes, solían involucrarse menos en las actividades agrícolas en sus tierras, prefiriendo arrendar tierras y el derecho de diezmar cuando podían. Hemos comprobado que ese proceso efectivamente se consolida hasta los finales de la Edad Media. Sin embargo, seguían manteniendo la gestión directa en algunas fincas y parroquias - sobre todo en las de Billingham en la orilla norte del río Tees. La parroquia de Billingham, y las tierras dentro de sus límites, representaban una de las partes más valiosas de las propiedades de los monjes. Así, los monjes seguían recaudando los diezmos de Billingham ellos mismos, a pesar de que esa parroquia no era la más cercana a

61 Durham Cathedral Muniments, bursars' accounts, 1509-10, 1510-11, 1511-12, 1512-13, 1513-14, 1514-15, 1515-16, 1519-20, 1536-37.

62 Durham Cathedral Muniments, bursars' accounts, 1510-11, 1511-12, 1512-13, 1513-14, 1514-15, 1515-16, 1519-20, 1536-37.

63 Durham Cathedral Muniments, bursars' accounts, 1519-20, 1536-37; Liddy, C.D. 2008. The Bishopric of Durham in the Late Middle Ages: 69-70 Woodbridge.

64 Durham Cathedral Muniments, bursars' accounts, 1506-7, 1507-8, 1508$9,1509-10,1510-11,1511-12,1512-13$, 1513-14, 1514-15, 1515-16, 1519-20, 1536-37.

65 Durham Cathedral Muniments, proctor of St Margaret's account, 1528-9. 
Durham. El dilema entre la recaudación directa o la venta de los diezmos y la venta fue menos importante durante el siglo $\mathrm{XV}$, debido a que los monjes recibieron una buena parte de los diezmos vendidos en especie. Por ello pudieron abastecer el monasterio no sólo con los productos adquiridos en el mercado, sino con los cosechados en sus fincas y mediante los cereales y productos de animales pagados en lugar de dinero. ${ }^{66}$

En la diócesis de Sevilla, desde la implantación del diezmo, se fue perfectamente consciente de que la recaudación directa de todas las variantes del tributo a lo largo y ancho de su inmenso arzobispado ${ }^{67}$ necesitaba un ejército de administradores que colapsaría el aparato de gestión del propio Cabildo Catedral. Es por ello, por lo que el Cabildo decidió ceder el cobro del diezmo de la mayor parte de las collaciones a particulares. Sólo se retenía el cobro directo en algunas parroquias, y siempre por motivos especulativos: bien porque se preveía que nadie iba a pagar el arrendamiento que el Cabildo pretendía ingresar de una fructífera parroquia (como los casos de los diezmos de pan y de vino de Jerez, o de aceite de Écija), o bien porque en la práctica el arrendamiento se había rematado en una cantidad muy baja para las expectativas del Cabildo. ${ }^{68}$ Esta venta de los diezmos es denominada por la institución como "arrendamiento de los diezmos".69

El complejo proceso de arrendamiento del diezmo estaba perfectamente estructurado, y se resume en las siguientes fases:

El Cabildo nombra a los hacedores ${ }^{70}$, quienes controlan territorialmente el proceso de arrendamiento del diezmo. Estos solían ser miembros del Cabildo o vicarios arzobispales. ${ }^{71}$

66 Dodds, B. 2005. "Managing tithes in the late middle ages", Agricultural History Review, 53: 127-133; Threlfall-Holmes, M. 2005. Monks and markets. Durham Cathedral Priory, 1460-1520: 139 Oxford.

${ }^{67} \mathrm{La}$ administración del diezmo en la diócesis hispalense correspondía al Cabildo Catedral, aunque el ámbito de su recaudación fuera todo un extensísimo arzobispado, que incluía las fértiles campiñas sevillanas (Marchena, Morón, Osuna, Carmona, Écija, Utrera y Lebrija), el fructífero bajo Guadalquivir (Jerez, Arcos, Sanlúcar, Rota y Puerto de Santa María), ricas tierras onubenses (en Niebla, Moguer, Huelva o Gibraleón) y del Aljarafe sevillano, entre otras muchas (Hernández Borreguero, J.J. 2010).

${ }^{68}$ Martín Riego, M. 1990.

69 La ya mencionada Ley de la Casa de Cuentas (LCC) también se denomina "ley y condiciones con que se arriendan y cogen las rentas de los diezmos de esta ciudad de Sevilla y su arzobispado (...)".

${ }^{70} \mathrm{Si}$ el hacedor es cualquier encargado de administrar una hacienda, en materia diezmal, se refiere a las personas que realizaban el hacimiento de los diezmos, procedimiento que culminaba con la subasta pública del arrendamiento de los mismos.

\footnotetext{
${ }^{71}$ ACS, Mayordomía, 01829.
} 
Estos hacedores, a su vez, delegarán la labor de estimar el montante de las cosechas (y por tanto del diezmo) en los llamados tazmeadores, de los que no hemos obtenido mucha información. ${ }^{72}$

El proceso de arrendamiento estaba condicionado por las fechas cercanas a la recolección, por lo que se regulan las fechas oportunas para realizarlo. ${ }^{73}$

El "remate de la renta" comenzaba con las subastas. Partiendo de la información de los tazmeadores, se realizaba la subasta en primera instancia en la sede de la vicaría correspondiente (conocido como remate a la vara).$^{74}$ El ganador de la subasta (futuro arrendador) tenía que esperar a que se celebrara en la sede del Cabildo Catedral el segundo juicio ${ }^{75}$, que finalizaba con el último remate. Tanto los ganadores de la primera subasta como los de la segunda y definitiva (si se readjudicaba el arrendamiento) tenían tres días para depositar fianzas suficientes ante el vicario correspondiente a la parroquia. ${ }^{76}$

A continuación el Cabildo otorgaba el documento, denominado recudimiento que autorizaba a cobrar a los contribuyentes los diezmos del producto especificado, y en la parroquia señalada. ${ }^{77}$ Este

72 José García Rodríguez nos puso en la pista de los documentos de 'tazmía' de la vicaría de Écija hacia mediados del siglo XVIII, (legajos situados en la sección Fondo Histórico General del Archivo de la Catedral de Sevilla), que debieron existir, tanto en períodos anteriores, como en todas las vicarías. Estos pliegos comienzan así: "Tazmía y aprecios regulados por el administrador de las rentas decimales de esta vicaría de Ecija, en virtud de informes de sujetos inteligentes y en particular del tazmeador de dicha vicaría, para los valores de las rentas (...) que stase han de rematar a la vara el día (...) y el último remate el día (...)". En la diócesis canaria los "tazmieros" pertenecían al clero rural adscrito a las diversas parroquias (Macías Hernández, A.M. 1986. "Fuentes para el estudio de la producción agraria en las Islas Canarias: el diezmo en la diócesis canariense (1480-1820)". Anuario de Estudios Atlánticos, 32: 298-299.

73 Este aspecto está regulado en los folios 19 a 25 de la LCC, ofreciendo fechas límites para la verificación y la subasta, según el tipo de producto (tipos de cereales, frutas, hortalizas, árboles, tipos de ganado...). Sin embargo, año tras año, las fechas se concretaban en el "Libro de comisiones para el cobro del diezmo (1573-1634)" (ACS, Mesa Capitular, 01969). En sus páginas se fijan las fechas concretas para subastar el trigo y cebada (mes de junio), o de la uva (entre mediados de agosto y finales de septiembre).

${ }^{74}$ LCC, folio 3.

${ }^{75}$ Martín Riego, M. 1990:116

${ }^{76}$ LCC, folios 5 y 36.

${ }^{77}$ LCC, folios 10 y 45. 
documento daba un derecho de cobro del impuesto que prescribía a los tres años. ${ }^{78}$

El arrendatario realiza el cobro del diezmo y liquida el tributo a todos los beneficiarios (arzobispo, rey, beneficiados), incluido el propio Cabildo Catedral. ${ }^{79}$ La LCC también especifica los plazos de pago según el tipo de producto recaudado (folios 16 a 18), que iban desde agosto del mismo año (para el pan), hasta mediados del año siguiente (para los diezmos del vino y de algunos animales). ${ }^{80}$

En caso de impago del arrendamiento del diezmo, se articula el proceso de ejecución de las fianzas recibidas. ${ }^{81}$

En la diócesis de Sevilla también era frecuente la venta del fruto decimal después del cobro del mismo. El objetivo de esta venta era aligerar la gigantesca cantidad de grano que había que entregar a cada miembro capitular, es decir, era una cuestión de logística. Volviendo a los datos del año 1534, hemos podido comprobar que los administradores de los diezmos, tras recibir todo el cereal, vendieron casi un tercio del trigo y prácticamente toda la cebada. Desconocemos ese dato concreto en unidades físicas, aunque sabemos que el importe neto de esa venta ascendió a 123.056 maravedíes. ${ }^{82}$

\section{DIEZMOS Y BUROCRACIA}

Hay pocos datos concretos sobre el aparato administrativo que utilizó el Cabildo Catedral de Sevilla para gestionar el diezmo durante la Edad Media. El órgano supremo de decisión era el propio Cabildo, mediante sus reuniones capitulares. Buena parte de la gestión económica estaba delegada

\footnotetext{
${ }^{78}$ LCC, folio 31.

${ }^{79}$ LCC, folio 17.
}

${ }^{80}$ En la diócesis de Canarias encontramos un proceso de arrendamiento muy similar. La principal diferencia estriba en que los diezmos de cereal no se arriendan, como regla general (Macías Hernández, M.A. 2011. "Diezmo y producto bruto agropecuario. El ejemplo de la diócesis canariense", Actas del X Congreso Internacional de la Asociación Española de Historia Económica: Carmona. Mayores diferencias pueden encontrarse, por ejemplo, en la diócesis de Valencia; así el Cabildo valenciano siempre recibía el cobro en metálico, y los contratos de "alquiler" se realizaban por cuatro años, por un mismo importe, para que el arrendatario compensara años buenos y malos de cosechas (Llibrer, I. 2011. "La Catedral de Valencia como administrador general del diezmo de la diócesis. Aspectos históricos, económicos, contables y organizativos", Actas del XVI Congreso de AECA: 11 Granada).

${ }_{81}$ LCC, folios 17 y 40.

${ }^{82}$ ACS, Mayordomía, 00011, apartado "cargo del comunal de las rentas del comunal (...)". 
en tres mayordomos ${ }^{83}$, quienes administraban los bienes e ingresos capitulares y se encargaban de su reparto entre los destinatarios. Éstos instrumentaban su poder mediante las llamadas mayordomías, que fueron tres desde la creación del Cabildo en el siglo XIII: la mayordomía del comunal, encargada de administrar los bienes destinados a las percepciones salariales de los canónigos y demás prebendados; la mayordomía de la pitancería, que estaba a cargo de los bienes dotados para culto funerario, procesiones y culto ordinario semanal; y la mayordomía de fábrica, que gestionaba las necesidades de culto y del mantenimiento del templo catedral $^{84}$.

De estas tres mayordomías o contadurías, la que asumió la gestión del impuesto diezmal fue la del comunal, siguiendo la lógica de que los ingresos de los diezmos que correspondían al Cabildo eran repartidos entre los capitulares. Este mayordomo dirigía todo el proceso de coordinación de las subastas, ${ }^{85}$ cobro y reparto del tributo. Para ello necesitaba de una serie de contadores y oficiales, normalmente elegidos entre los racioneros y los clérigos de la veintena. ${ }^{86}$ Periódicamente las reuniones capitulares recibían las rendiciones de cuentas de los mayordomos, ya fuera en materia diezmal o de cualquier otro ámbito económico.

Además de los contadores y oficiales adscritos a la mayordomía, se instrumentaron otra serie de cargos periféricos: los ya mencionados hacedores (normalmente vicarios o sacerdotes locales) y tazmeadores, intervenían puntualmente en la fase de subastas de los diezmos; por su parte, los fieles eran los encargados de cobrar los diezmos (cuando se gestionaba en fieldad), almacenarlos, venderlos (cuando se creía conveniente) y repartirlo entre sus beneficiarios.

Todo este proceso administrativo puede identificarse, más que por las normas, por lo recogido en los libros de cuentas correspondientes. Se conservan una cantidad significativa de estos libros en el Archivo de la Catedral de Sevilla. A continuación exponemos brevemente su funcionamiento:

83 Debido a la alta responsabilidad que conllevaba el cargo de mayordomo, solo podía desempeñarlo "quien tuviere la orden sagrada"; es decir, era necesario ser sacerdote.

${ }^{84}$ Pérez-Embid, J. 1978.

${ }^{85}$ El LCC (folio 9) señala que la segunda subasta de los diezmos (que antes denominamos segundo juicio) se debía realizar ante el mayordomo del comunal.

${ }^{86}$ Los clérigos de la veintena eran sacerdotes dependientes del Cabildo, que cantaban todos los ritos de las horas (primas, nonas, etc). Gozaban de un salario fijo, y eran elegidos "por oposición de canto y escogida voz" (Gómez Bravo, J. 1645. "Discursos sobre la grandeza de la Iglesia Catedral de Sevilla": Biblioteca Capitular, legajo 59/5/26, 1645). Debido a que percibían una remuneración baja, compatibilizaban esa labor con "otros menesteres" que no se aclaran. 
A continuación describimos los 6 tipos de libros de cuentas de diezmos de los siglos XIV y XV:

Libros de calendarios de subastas y hacimiento (varios, siglo $\mathrm{XVI)}$. Recogen datos sobre fechas de subastas en cada parroquia, así como el pago de las dietas a los responsables que se desplazaron para realizarlas.

Libros de diezmos (unos 20 libros, siglo XVI). Registran el resultado de cada subasta en cada parroquia de la diócesis, indicando el nombre del arrendatario, importe, incluso el reparto de esa cifra entre sus beneficiarios.

Libros de fieldades (siglo $\mathrm{XVI}$ ). Anotan todas las entradas (contribuyentes) y salidas (gastos de administración) de las parroquias donde se cobró el diezmo directamente por el Cabildo. Ofrecen un alto nivel de detalle, así como el nombre de los contribuyentes ordenados por calles.

Libros de pan y maravedíes. Casillas (siglo XVI casi completo). Están dedicados a registrar los cobros previstos de cada una de las parroquias, separando los cereales del dinero líquido, para calcular el montante el provisional de cada año. El mismo libro realiza el reparto previsto entre cada uno de los capitulares. Por tanto, en ningún momento se registran cobros y pagos, sino presupuestos anuales.

Libros de las rentas de los diezmos de pan y excusados (siglo $\mathrm{XVI}$ casi completo). Secuencialmente siguientes a los anteriores anotan los cobros recibidos de los diezmos, tanto los que envían los fieles, como los que entregan los arrendatarios.

También Durham ha conservado una enorme cantidad de cuentas relacionadas con los diezmos: más de 1.200 cuentas, que contienen unos 16.000 ingresos diezmales ${ }^{87}$. A lo largo de la Baja Edad Media, la burocracia evoluciona continuamente, aunque cabe destacar la introducción de un nuevo sistema contable para facilitar la gestión del diezmo.

Todas las grandes instituciones eclesiásticas inglesas que recibían diezmos en la Baja Edad Media registraban sus ingresos en pergamino. En el caso de los monasterios benedictinos, el Capítulo General de la Orden se empeñó en que los monjes guardasen cuentas de los ingresos y gastos, un

87 Dodds, B. 2007: 23. 
mandato que fue reafirmado por el Papa en $1336 .^{88}$ Sin embargo, había varios tipos de documentos donde se registraban los ingresos diezmales. En el caso de Durham, se encuentra mucha información sobre dichos ingresos en las cuentas globales de los monjes encargados de aspectos de la vida monástica, como el bursarius y el hostillarius. En otros centros recaudadores de diezmos existieron diversos tipos de registros contables. ${ }^{89}$ Por ejemplo, los obispos de Winchester guardaban una serie de cuentas para sus dos parroquias de Hambledon y East Meon (Hampshire). ${ }^{90}$ Se conservan pocas de esas cuentas parroquiales en los archivos de Durham Priory pero hay algunos ejemplos, como las series de cuentas de los proctors de St Oswald's y de St Margaret's, cada uno de ellos encargado de recibir una porción de los ingresos de la parroquia de St Oswald's, una de las mayores en extensión que incluía, además, la propia ciudad de Durham. ${ }^{91}$ Las parroquias adscritas a una corporación religiosa solían incorporar en su rendición de cuentas las de las tierras señoriales pertenecientes a la corporación, pues resultaba más fácil preparar una sola cuenta con los diezmos y los ingresos de las cosechas de las tierras señoriales. Aunque los monjes de Durham solían anotar sus ingresos diezmales en las cuentas centrales de la institución, a principios del siglo XIV anotaban algunos ingresos diezmales en las cuentas preparadas para sus tierras señoriales. Por ejemplo, en 1299-1300, anotaban los recibos diezmales de cebada, guisantes y avena en la cuenta para las tierras señoriales de Ketton. ${ }^{92}$

Como se indica en esta descripción de los tipos de documentos donde se encuentran diezmos, la manera de anotar tales recibos cambiaba a lo largo de la Edad Media en Durham. El desarrollo más importante fue la introducción de un sistema para registrar los diezmos recibidos como grano en cuentas de dinero. Consiguieron esto haciendo una valoración de la cantidad de grano y dando entrada a la valoración en las secciones de la cuenta para recibos y gastos. Es decir, anotaban una entrada de dinero ficticia. Por este sistema, resultaba posible que los auditores comparasen el valor de los diezmos vendidos por dinero y los diezmos recibidos en especie

88 Dobie, A. 2008. "The development of financial management and control in monastic houses and estates in England c. 1200-1540", Accounting, Business \& Financial History, 18: 150.

${ }^{89}$ Véase por ejemplo Kershaw, I. Smith D. y Cooper. D.M. 2000. The Bolton Priory Compotus, 1286-1325: Together with a priory account roll for 1377-78: 554-5 York; Canterbury Cathedral Archives, Almoner's account 1372-3.

90 Page, M. 1996. "The Pipe Roll of the bishopric of Winchester, 1301-2". Hampshire Record Series, 14: 291-6 y 303-4; Page, M. 1999. "The Pipe Roll of the bishopric of Winchester, 1409-10". Hampshire Record Series, 16: 273-81 y 291-2.

${ }^{91}$ Dodds, B. 2007: 24.

92 Durham Cathedral Muniments, Ketton manor account, 1299-1300. 
usando solo un documento. Introdujeron este sistema a finales del siglo XIV y se mantuvo vigente hasta el cierre del monasterio en $1540 .^{93}$

Las cuentas que sobreviven hasta hoy suelen ser las últimas versiones, preparadas para presentación a los auditores. Los monjes y los escribanos que preparaban las cuentas debieron haber usado otros documentos, como borradores y apuntes, conteniendo los datos para las propias cuentas. Por supuesto, se sabe poco de este tipo de documentación. En algunos casos, preparaban contratos para la venta del diezmo. Por ejemplo, Reginald de Haswell aceptó comprar los diezmos de Eden y South Sherburn, pertenecientes a los monjes de Durham, en 1342. Hicieron un contrato en el día 1 de agosto: Reginald iba a pagar en los días 20 de marzo y 24 de junio en 1343. ${ }^{94}$ Tales contratos sobreviven en una proporción muy pequeña de todas las ventas de diezmos en Durham, pero es probable que hicieran algún tipo de documento en todos los casos para asegurar el pago. El documento más interesante para entender el sistema de la recaudación de los diezmos es un libro redactado por el bursarius en 1495-6. Vemos en el libro que los monjes apuntaban sus ingresos en dinero pero, muchas veces, los recibían en una variedad de productos. Por ejemplo, en 1495-6, Thomas Jakson compró los diezmos de Sheraton por $£ 4$ y realizó una parte de su pago en cinco bueyes, tasados en 50s., y cuatro vacas, tasadas en $28 \mathrm{~s}^{95}$. Estos y otros ejemplos son importantes porque muestran la discrepancia entre la realidad y la impresión dada por las cuentas.

\section{CONCLUSIONES}

A pesar de las diferencias obvias en el clima, la geografía y las tradiciones jurídicas y sociales ingleses y españoles, las economías de los dos países a fines de la Edad Media no eran tan distintas. Ambos sistemas económicos dependían de la agricultura: los dos países producían materias primas, sobre todo cereales y productos pecuarios. Se ven estas similitudes en los diezmos, sobre todo en la importancia de los diezmos de cereales en la diócesis de Sevilla y en las parroquias pertenecientes a los monjes de Durham. Por supuesto, había diferencias importantes también, como la importancia de la uva y el olivo en la diócesis de Sevilla, productos que no se podían cultivar en el noreste de Inglaterra.

93 Dodds, B. 2005.

94 Durham Cathedral Muniments, Miscellaneous Charters, 3957; Dodds, B. 2002. "Durham Priory tithes and the Black Death between Tyne and Tees", Northern History, 39: 6.

95 Lomas, R.A. y Piper, A.J. 1989. "Durham Cathedral Priory rentals, 1: Bursar's rentals", Surtees Society, 198: 192; Threlfall-Holmes, M. 2005: 141. 
El funcionamiento del sistema del diezmo en Durham y en Sevilla, como en otras partes de Europa, llevó al pago de cantidades enormes de productos agrícolas a la Iglesia. Por eso, la Iglesia tenía un papel comercial tan importante. Como hemos señalado las instituciones y miembros eclesiales dispusieron de más del diez por ciento de la cosecha que ponían en el mercado los agricultores, pues de la base impositiva no se restaban las grandes cantidades que necesitaban como simiente y para su propio consumo familiar.

El volumen de productos recibidos en concepto de diezmo era tan enorme que los párrocos, los monjes y los miembros de comunidades religiosas no podían consumir más que una pequeña proporción. Por ello vendían grandes cantidades de diezmos, a veces antes de la recolección del impuesto, a veces en el mismo momento del cobro, y otras veces después de su recogida y almacenamiento. Dado la importancia comercial del diezmo, su venta/arrendamiento era una actividad económica importante en Inglaterra y España en esa época. Algunos compradores esperaban grandes beneficios por la especulación, intentando preveer la cantidad de productos que recaudarían de los diezmos, y el de los precios de venta para estos productos en el año que venía. En algunos casos los compradores de los diezmos eran los propios agricultores: en cierto modo compraban la exención del impuesto. En otros casos, los compradores eran mercaderes, intentando obtener mayores beneficios acumulando las provisiones antes de venderlas. A veces, los compradores de los diezmos eran clérigos ellos mismos, aprovechándose de su familiaridad con el sistema de diezmos y con los fieles que pagaban para obtener unos ingresos suplementarios. En definitiva, el diezmo era un rasgo importante del funcionamiento de las economías de Inglaterra y de España.

A pesar de las similitudes halladas, existía una diferencia fundamental en la organización del diezmo en los dos países. El sistema del tributo en España era mucho más centralizado que en Inglaterra. En los diezmos ingleses el único beneficiario era el cura titular de la respectiva parroquia, mientras que en España existía un conglomerado de perceptores de su ingreso: locales (curas y templo parroquial), diocesanos (cabildo catedralicio y obispo) y real. El sistema inglés propició que se tributara según la costumbre parroquial, frente a la tendencia reguladora de cada diócesis española para establecer una norma que detallara todo el proceso del cobro diezmal. Por lo menos en el caso de las diócesis en el sur de España, esto parece haber sido resultado de la Reconquista, que permitió la organización de un sistema de parroquias y diezmos. En Inglaterra, al contrario, no hubo tal iniciativa de organización: el sistema de las parroquias y los diezmos ligados a ellas, se desarrolló lentamente, y de maneras muy distintas en cada diócesis y región.

Sin embargo, si analizamos y comparamos el alto nivel de centralización en la organización de los diezmos en España con el sistema más descentralizado en Inglaterra las diferencias prácticas no fueron tan significativas. En ambos países, cantidades enormes de diezmos llegaban a 
los almacenes y los erarios de los ricos capítulos catedralicios, de los monasterios, y de los clérigos más poderosos. Para los párrocos, que apenas sobrevivían de lo que percibían por administrar los sacramentos a la mayoría de los laicos, y que mantenían a duras penas sus templos parroquiales, mucho dependía de la suerte. En Inglaterra como en España, el sistema de reparto de los diezmos hacía ricos a algunos clérigos y otros quedaban en la miseria. En nuestro caso concreto, los capitulares de Sevilla disfrutaron de unas altas rentas personales, mientras que los monjes de Durham llevaron una vida acomodada, amparados por la riqueza que atesoraba la institución a la que pertenecían.

\section{FUENTES Y BIBLIOGRAFÍA CITADAS}

Aldea, Q. 1973. La economía de las iglesias locales en la Edad Media y Moderna. Hispania Sacra, 26:51-52.

Caley, J. y Hunter, J., (eds.). 1825. Valor ecclesiasticus temp. Henr.

VIII. auctoritate regia institutus. v. 5, Londres.

Canga Argüelles, J. 1883. Diccionario de Hacienda, con Aplicación a España. Madrid.

Clark, G. 2004. "The price history of English agriculture, 1209-1914". Research in Economic History, 22.

Costa y Belda, E. 1978. "Las Constituciones de don Raimundo de Lasaña para el Cabildo de Sevilla". Historia, Instituciones y Documentos. Sevilla. Universidad de Sevilla.

Díaz J.R. y Guinot, E. 2008. "La dîme dans l'Espagne médiévale", Actes des XXXes Journées Internationales d'Histoire de l'Abbaye de Flaran.

Dobie, A. 2008. "The development of financial management and control in monastic houses and estates in England c. 1200-1540", Accounting, Business \& Financial History, 18: 150.

Dodds, B. 2005. "Managing tithes in the late middle ages". Agricultural History Review, 53.

Dodds, B. 2007. Peasants and production in the medieval North-East: the evidence from tithes, 1270-1536. Woodbridge, Boydell.

Garzón Pareja, M. 1974. Diezmos y tributos del clero de Granada. Granada, Archivo de la Real Chancillería.

Harvey, M. M. 2006. Lay Religious Life in Late Medieval Durham. Woodbridge, Boydell and Brewer. Press.

Heath, P.M.A. 1964. Medieval Clerical Accounts. York, St. Anthony's

Hernández Borreguero, J.J. 2010. El Cabildo Catedral de Sevilla: economía y esplendor (siglos XVI y XVII). Ayuntamiento de Sevilla.

Kent et al. 2002. 'North Division: Hornsea', A History of the County of York East Riding: Volume 7: Holderness Wapentake, Middle and North Divisons: 273-295. [http://www.british- 
history.ac.uk/report.aspx?compid=16153, visto el 29 de septiembre 2011]. Heath, P.M.A. 1964. Medieval Clerical Accounts: York.

Kershaw, I. Smith D. y Cooper. D.M. 2000. The Bolton Priory Compotus, 1286-1325: Together with a priory account roll for 1377-78: 554-5 York.

Ladero M.A. y González, M. 1978. Diezmo eclesiástico y producción de cereales en el reino de Sevilla (1408-1503): Sevilla.

Latorre Ciria, J. M. 1992. Economía y religión. Las rentas de la catedral de Huesca y su distribución social (siglos XVI-XVII). Institución Fernando el Católico e Instituto de Estudios Altoaragoneses.

Liddy, C.D. 2008. The Bishopric of Durham in the Late Middle Ages. Woodbridge, Boydell.

Little, A. G. 1945. "Personal tithes"'. English Historical Review, 60.

Lomas, R.A. y Piper, A.J. 1989. "Durham Cathedral Priory rentals, 1: Bursar's rentals", Surtees Society, 198: 192.

Macías Hernández, A.M. 1986. "Fuentes para el estudio de la producción agraria en las Islas Canarias: el diezmo en la diócesis canariense (1480-1820)". Anuario de Estudios Atlánticos, 32.

Martín Riego, M. 1990. Diezmos eclesiásticos, rentas y gastos de la mesa arzobispal hispalense (1750-1800): Sevilla.

McNeill J.T y Gamer. 1990. Medieval handbooks of penance: a translation of the principal 'Libri Poenitentiales' and selections from related documents: 212 New York.

Montes Romero-Camacho, I. 1998. Propiedad y explotación de la tierra en la Sevilla de la Baja Edad Media: el patrimonio del Cabildo-Catedral: 344 Sevilla.

Moorhouse, G. 2008. The last office: 1539 and the dissolution of a monastery: 185-200 London.

Morales Alonso, J.P. 1883. Tratado de Derecho Eclesiástico general y particular de España. Vols I-II, Sevilla.

Nieto Soria, José Manuel. 1984. La conflictividad en torno al diezmo en los comienzos de la crisis bajomedieval castellana (1250-1315). Anuario de estudios medievales, 14: 211-235.

Oakley, A. 1996. "Rochester Priory, 1185-1540" en Faith and fabric: a history of Rochester Cathedral: 604-1540 Woodbridge.

Page, M. 1996. "The Pipe Roll of the bishopric of Winchester, 1301-2". Hampshire Record Series, 14: 291-6 y 303-4.

Page, M. 1999. "The Pipe Roll of the bishopric of Winchester, 140910". Hampshire Record Series, 16: 273-81 y 291-2.

Pérez-Embid, J. 1977. "El Cabildo Catedral de Sevilla en la Baja Edad Media". Hispania Sacra, Revista de historia eclesiástica. Separata del volumen XXX.

Piper, A.J. 2005. "The size and shape of Durham's monastic community" en North-East England in the later middle ages: 154 Woodbridge. 
Robinson, W. R. B. 1983. "The Valor Ecclesiasticus of 1535 as evidence of agrarian output: tithe data for the deanery of Abergavenny". Bulletin of the Institute of Historical Research, 56.

Rollanson D. y Dobson, R.B. 2004. "Cuthbert [St Cuthbert] (c.635687)", Oxford Dictionary of National Biography, Oxford.

Rubio Merino, P. 1997. "Los archivos eclesiásticos de la archidiócesis de Sevilla". Conferencia dentro del 'Curso sobre los Archivos Vaticanos y Sevillanos de la Iglesia Católica: del secreto a la apertura': Sevilla.

Rubio Merino, P. 2001. "Los archivos eclesiásticos". Iglesia y religiosidad en España: Historia y Archivos: Guadalajara.

Scarisbrick, J. J. 1960. "Clerical taxation in England, 1485-1547". Journal of Ecclesiastical History, 11.

Swanson, R.N. 1989. Church and Society in Late Medieval England. Oxford, Basil Blackwell.

Swanson, R. N. 2008. "A universal levy: tithes and economic agency" en Agriculture and Rural Society after the Black Death: Common themes and regional variations, ed. B. Dodds and R. H. Britnell. Hatfield, University of Hertfordshire Press.

Threlfall-Holmes, M. 2005. Monks and markets. Durham Cathedral Priory, 1460-1520. Oxford, Oxford University Press. 